\title{
CD5 Expressing Cell Measurement
}

National Cancer Institute

\section{Source}

National Cancer Institute. CD5 Expressing Cell Measurement. NCI Thesaurus. Code C103369.

A count of the CD5 expressing cells per unit of a biological specimen. 